\title{
INFLUENCE OF ENVIRONMENTAL, ERGONOMIC FACTORS AND PROPERTIES OF OPERATORS ON THE RELIABILITY OF SHIPS PROPULSION SYSTEMS
}

\author{
Wojciech Frąckowiak \\ Gdynia Maritime University, Department of Engineering Sciences \\ Morska Street 81-87, 81-225 Gdynia, Poland \\ tel.: +4894 3478344, fax: +48586901-331 \\ e-mail:wojt@am.gdynia.pl
}

\begin{abstract}
Analyzing the systems in terms of reliability, we often treat them as the technical objects only, omitting human interaction or assuming that operator has constant characteristics. This significantly distorts the results obtained in this way, since human is a part of the system with special properties that can change together with the predisposition of the operator and the conditions under which he operates. These attributes may have a major influence on the reliability of the systems. Therefore, analysis of systems reliability should include a reliability of operator and its properties. In this paper presented the antropotechnical reliability structure based on selected installation, which is a part of ships propulsion system. Also operator's functions were defined and the analysis of human reliability, taking into account various properties of the operator and the external conditions, were performed. Then, there is assessed the influence of operator and environmental factors on the value of the entire system reliability. The study used the reliability data of the container ship propulsion system equipped with low-speed piston engine, fixed pitch propeller and auxiliary installations. These data were obtained from studies of expert judgments (Brandowski A., Frackowiak W. et al.) in the years 2007-2009. For HRA (human reliability analysis), HEART technique (Human Error Assessment and Reduction Technique) was used, together with the human unreliability values and correction factors developed by the authors of this method. Study results illustrate influence of environmental, ergonomic factors and the properties of the operator on the reliability of the antropotechnical systems. The studies were subjected exemplification on fuel treatment installation as a part of ships propulsion systems.
\end{abstract}

Keywords: propulsion system, operator, reliability, analysis, operator functions, Performance Shaping Factors

\section{Introduction}

The safety of the ship, its cargo and crew mainly depends on the reliability of the propulsion system (PS). Loss of ship propulsion function is one of the most dangerous hazardous events in shipping. Under certain environmental conditions can leads to loss of the ship with people and cargo located onboard. The PS reliability depends on the reliability of the technical elements, its composition, structure and reliability of the operator performing the functions assigned to him. It follows that the PS of the vessel to be treated as an antropotechnical object. When assessing the reliability of such systems is often assumed that an operator has a permanent, unchanging property and assumed his reliability as a constant value independent of the human properties, ergonomic and environmental conditions under which he works. Such an approach may considerably distort the reality, because human is a specific element of the system which has properties that may change depending on the predisposition of the operator and the external conditions. Therefore the characteristics of the operator and the conditions under which he carries out assigned functions should be taken into account when analyzing the reliability of the PS.

\section{Definition and model of the propulsion system reliability}

Reliability as a subject of the analysis is related to the loss by the PS system of its capability of performing the assigned function, i.e. generating the driving force of a defined value and direction. 
It appears as an effect of a catastrophic failure (CF) of the PS. Such failure may cause immediate (ICF) or delayed (DCF) catastrophic failure of the PS. In the second case the stoppage is connected with renewal, which may be carried out at any selected time. It is obvious that only the former case of the forced stoppage creates a risk of damage or even loss of ship - it is a hazardous event [3,5]. We define the PS reliability as the probability that the ICF type of PS failure does not occur during specified period of time.

Due to the fact that the ships systems are repairable and renewal time may be considered as negligibly short, excluding the planned class renewal repairs connected with stay in a ship repair yard, following assumptions about the form of the PS reliability models may be adopted $[3,5]$ :

- in the case of PS reliability, we are interested only in the "active" phase of ship operation. We shall exclude from the model the periods of stays in ship repair yards or in other places connected with renewals of the ship equipment,

- the investigated system may be only in the active usage or stand-by usage state. The ICF type PS failures may occur only in the first of those states,

- the PS reliability model is the renewal process with negligibly repair time and with an exponential probability function of time between failures. The exponential time distribution function is characteristic of a normal operation of many system classes, including also the ship systems $[6,7]$.

Therefore, the exponential model of PS reliability has the form:

$$
P\{t\}=e^{-\lambda^{(a)} t},
$$

where:

$P\{t\}$ - probability that the system will not damage to the time $t$,

$\lambda^{(a)}-$ ICF type failure rate,

$t \quad-$ active usage time,

Data related to the ICF type failure rates of PS elements were obtained from research on the expert judgments (Brandowski A., Frąckowiak W. et al.) in the years 2007-2009 [2, 4, 5].

\section{Operator reliability model}

In antropotechnical systems operator is considered as a specific element. Because of performing assigned to him function he may fail in such a way: not perform the scheduled tasks, carry out them incorrectly or make actions leading to the degradation of the system ability to realize its functions. Reliability of the operator performing assigned function may vary with the individual properties of human and environmental or ergonomics conditions under which he works at the time. During human activities modelling for systems reliability assessment, it is necessary to take into account such factors. They are defined as Performance Shaping Factors (PSF) and are divided into external and internal. The external PSF cover the entire working environment, especially the construction of equipment and machinery, written and oral instructions. Whereas the internal PSF are related to the individual characteristics of persons, their skills, motivation and expectations [1].

Human Reliability Analysis (HRA) was used for estimation of the operator reliability. There are several methods of HRA, one of them is HEART (Human Error Assessment and Reduction Technique) developed by J.C. Williams [8]. It is characterized by simplicity of analysis, small reliability data requirements and, what is important takes into account, human tasks, ergonomic and environmental factors that negatively affect the performance of those tasks. Authors of the HEART method have developed an "operators general tasks" table with corresponding to them nominal value of human failure probability. They have created also the PSF list with correction factors. Sample values of these parameters are given in Tab. 1. and 2. To determine the reliability of the operator performing assigned function we need to match the task from Tab. 1 with analyzed 
one and PSF from Tab. 2 with the possible factors affecting the operator. Then the subjective value of PSF weights must be defined. Reliability of the operator performing the task $O P_{i}$, taking into account PSF factors, is calculated from (2):

$$
R_{O P i}=1-\left[F_{i} \cdot \prod_{k=1}^{n}\left\{\left(C_{k}-1\right) \cdot W_{i k}\right\}\right],
$$

where:

$R_{O P i}$ - reliability of the operator performing $O P_{i}$ function,

$F_{i} \quad$ - nominal value of human unreliability performing $O P_{i}$ function,

$C_{k} \quad$ - value of PSF correction factor,

$W_{i k}$ - subjective value of PSF correction factor weight for $O P_{i}$ function.

Tab. 1. Examples of general tasks and the nominal values of human unreliability [1]

\begin{tabular}{|ll|r|}
\hline \multicolumn{1}{|c|}{ General tasks } & $\begin{array}{c}\text { Nominal value of human } \\
\text { unreliability }-F_{i}\end{array}$ \\
\hline A) & $\begin{array}{l}\text { Completely unknown, performed quickly without realizing the } \\
\text { possible consequences }\end{array}$ & 0.55 \\
\hline B) & $\begin{array}{l}\text { Restoration or causing a new status of the system without supervision } \\
\text { or procedures }\end{array}$ & 0.26 \\
\hline C) & Complex task that requires high level reasoning and skill & 0.16 \\
\hline D) & Simpler tasks done quickly and with insufficient attention & 0.09 \\
\hline E) & $\begin{array}{l}\text { Routine, well-practiced, quick tasks requiring a relatively low level of } \\
\text { skill }\end{array}$ & 0.02 \\
\hline F) & $\begin{array}{l}\text { Restoration or causing a new state of the system according to the } \\
\text { procedures }\end{array}$ & 0.003 \\
\hline
\end{tabular}

Tab. 2. Examples of PSF with corresponding values of correction factors [1]

\begin{tabular}{|l|r|}
\hline \multicolumn{1}{|c|}{ PSF } & Correction factors $-C_{k}$ \\
\hline Lack of available time for fault detection and correction & $\mathrm{x} 11$ \\
\hline Operator inexperience & $\mathrm{x} 3$ \\
\hline Favourable conditions for selecting incorrect procedure & $\mathrm{x} 2$ \\
\hline
\end{tabular}

\section{Case study}

The main engine fuel supply system was used for study exemplification. This subsystem is a part of PS of container ship equipped with low-speed piston engine, fixed pitch propeller and auxiliary subsystems. Fig. 1 shows the reliability structure of this installation including the operator reliability blocks (OP). It is based on the structural diagram of real installation, decomposed to the equipment level. This analysis includes human influence on the system reliability only during active usage time of the technical elements. Operator interaction during renewal process is excluded from consideration. 


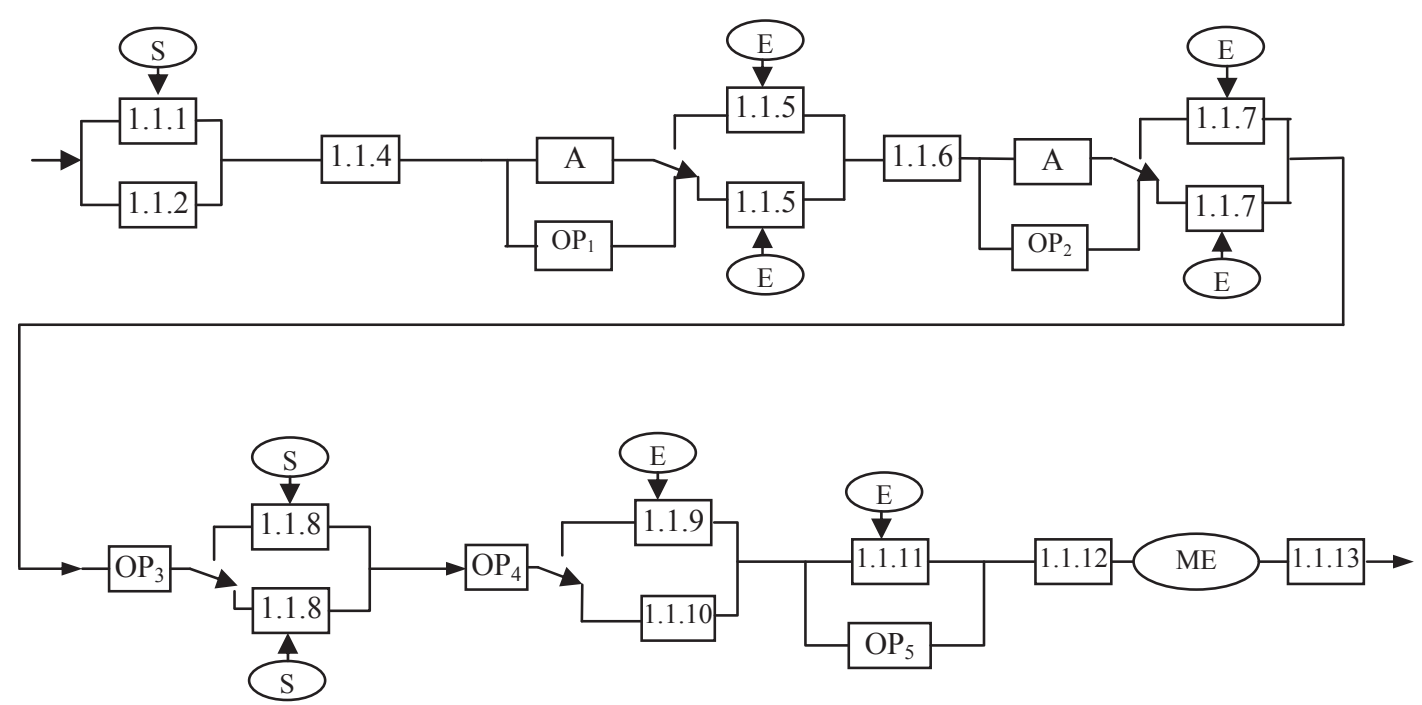

Fig. 1. Reliability structure block diagram for fuel supply system

where:

1.1.1 - Heavy fuel oil tank with mounted valves and steam heating system;

1.1.2 - Diesel oil tank with mounted valves and steam heating system;

1.1.4 - Fuel oil pipes from tanks to supply pumps with steam heating system and equipment (valves, temperature and fuel pressure sensors);

1.1.5ab - Supply pumps (from the suction to discharge valve) with electric motors;

1.1.6 - Low pressure fuel oil pipes with steam heating system and equipment (valves, temperature and fuel pressure sensors);

1.1.7ab - Circulating pumps (from the suction to discharge valve) with electric motors;

1.1.8ab - Fuel heaters with shut-off valves and steam heating system;

1.1.9 - Automatic fuel fine filter;

1.1.10 - Backup fuel fine filter;

1.1.11 - Fuel viscosity control system;

1.1.12 - Fuel oil pipes with steam heating system and equipment (valves, temperature and fuel pressure sensors);

1.1.13 - Fuel oil return pipes with steam heating system and equipment (valves, temperature and fuel pressure sensors);

A - Automatic starter of stand-by equipment;

OP - Operator;

E $\quad-$ Electric power supply;

S - Steam supply;

ME - Main engine.

The installation creates a complex reliability structure composed of basic modules (parallel, stand-by redundant, etc.). Blocks representing the reliability of the operator performing the assigned functions were described as:

- OP1 - manually start of the standby fuel supply pump in the event of active pump and automatic starter (A) failure, (operator performs the function of a backup trigger in standby redundant structure),

- OP2 - manually start of the circulating fuel pump in the event of active pump and automatic starter (A) failure, (operator performs the function of a backup trigger in standby redundant structure),

- OP3 - change over the fuel and steam valves in order to start the stand-by heater in the event of active heater failure, (operator performs the function of a trigger in standby redundant structure),

- OP4 - change over the fuel valves in order to start the stand-by filter in the event of active filter failure, (operator performs the function of a trigger in standby redundant structure), 
- OP5 - manually control the viscosity of heavy fuel oil (operator is a reserve of automatic control in a parallel structure).

The HEART method was used for determining the reliability of the blocks representing the operator functions. After a preliminary analysis it was assumed that all functions may be classified as the "E" type task, i.e. "Routine, well-practiced, quick tasks requiring a relatively low level of skill" with the corresponding value of the human unreliability - 0.02 (Tab. 1). For case study examples of PSF were selected from Tab. 2:

- PSF 1 - Lack of available time for fault detection and correction,

- PSF 2 - Operator inexperience,

- PSF 3 - Favourable conditions for selecting incorrect procedure.

Tab. 3. Summary of the nominal value of human unreliability, together with the selected PSF correction factors $C_{i k}$ and subjective value of weight $W_{i k}$

\begin{tabular}{|c|c|c|c|c|c|c|c|}
\hline \multirow[b]{2}{*}{$\begin{array}{l}\text { Operator } \\
\text { function }\end{array}$} & \multirow{2}{*}{$\begin{array}{l}\text { Nominal } \\
\text { value of } \\
\text { human } \\
\text { unreliability } \\
\quad\left(F_{i}\right)\end{array}$} & \multicolumn{2}{|c|}{ PSF 1} & \multicolumn{2}{|c|}{ PSF 2} & \multicolumn{2}{|c|}{ PSF 3} \\
\hline & & $\begin{array}{l}\text { Correction } \\
\text { factor }\left(C_{i 1}\right)\end{array}$ & $\begin{array}{c}\text { Weight } \\
\left(W_{i l}\right)\end{array}$ & $\begin{array}{l}\text { Correction } \\
\text { factor }\left(C_{i 2}\right)\end{array}$ & $\begin{array}{c}\text { Weight } \\
\left(W_{i 2}\right)\end{array}$ & $\begin{array}{l}\text { Correction } \\
\text { factor }\left(C_{i 3}\right)\end{array}$ & $\begin{array}{c}\text { Weight } \\
\left(W_{i 3}\right)\end{array}$ \\
\hline OP1 & 0.02 & 11 & 0.5 & 3 & 0.9 & 2 & 0.6 \\
\hline OP2 & 0.02 & 11 & 0.7 & 3 & 0.9 & 2 & 0.8 \\
\hline OP3 & 0.02 & 11 & 0.5 & 3 & 0.9 & 2 & 0.6 \\
\hline OP4 & 0.02 & 11 & 0.7 & 3 & 0.9 & 2 & 0.8 \\
\hline OP5 & 0.02 & 11 & 0.5 & 3 & 0.9 & 2 & 0.6 \\
\hline
\end{tabular}

Tab. 4. Obtained values of operators reliability considering selected PSF

\begin{tabular}{|l|r|r|r|r|}
\hline $\begin{array}{c}\text { Operator } \\
\text { function }\end{array}$ & PSF 1 & \multicolumn{1}{|c|}{ PSF 2 } & PSF 3 & \multicolumn{2}{c|}{$\begin{array}{c}\text { PSF 1 + } \\
\text { PSF 2 }+ \\
\text { PSF 3 }\end{array}$} \\
\hline OP1 & 0.88 & 0.944 & 0.968 & 0.768 \\
\hline OP2 & 0.84 & 0.944 & 0.964 & 0.634 \\
\hline OP3 & 0.88 & 0.944 & 0.968 & 0.756 \\
\hline OP4 & 0.84 & 0.944 & 0.964 & 0.634 \\
\hline OP5 & 0.88 & 0.944 & 0.968 & 0.768 \\
\hline
\end{tabular}

Nowadays operators task during active operation of the PS were reduced mainly to respond to information from the alarm and monitoring systems and starting reserve equipment in case of failure of basic one. Therefore, the operator in such systems acts as a backup component, or "trigger". He carries out his functions only "on demand" i.e. only in the event of damage to the active device. The time required to perform these tasks is relatively short compared to the PS active usage time. When considering these we conclude that the operator reliability $R_{O P i}$ not dependents of time and take constant values for any time interval of estimation. Tab. 5. shows the ICF type failure rates $\left(\lambda^{(a)}\right)$ of the fuel supply system devices obtained from expert judgment during research in the years $2007-2009$ [2, 4, 5]. Assuming an exponential distribution of time to failure of technical components of the system, reliability of the installation was determined by formulas for basic reliability structures available in the literature [7].

Table 6 and Fig. 2 shows the results of fuel supply systems reliability analysis including selected internal and external factors PSF adversely affecting human activities. Estimation was carried out for different prediction time intervals (from 6 to 36 months). 
Tab. 5. ICF type failure rates $\left(\lambda^{(a)}\right)$ of the fuel supply system devices [2, 4, 5]

\begin{tabular}{|c|l|c|}
\hline No & \multicolumn{1}{|c|}{ Device } & $\lambda_{\mathrm{a}}[1 / \mathrm{h}]$ \\
\hline 1 & Service tank & $1,77994 \mathrm{E}-06$ \\
\hline 2 & Supply pump & $1,26376 \mathrm{E}-05$ \\
\hline 3 & Circulating pump & $1,26376 \mathrm{E}-05$ \\
\hline 4 & Oil heater & $5,16183 \mathrm{E}-06$ \\
\hline 5 & Filter & $1,31716 \mathrm{E}-05$ \\
\hline 6 & Viscosity control arrangement & $1,54855 \mathrm{E}-05$ \\
\hline 7 & Piping + heating up steam arrangement & $1,05313 \mathrm{E}-06$ \\
\hline
\end{tabular}

Tab. 6. The results of fuel supply system reliability prediction for selected PSF

\begin{tabular}{|l|c|c|c|c|c|c|}
\hline \multirow{2}{*}{ PSF type } & \multicolumn{7}{|c|}{ Estimation time interval [Months] } \\
\cline { 2 - 7 } & $6 \mathrm{M}$ & $12 \mathrm{M}$ & $18 \mathrm{M}$ & $24 \mathrm{M}$ & $30 \mathrm{M}$ & $36 \mathrm{M}$ \\
\hline No adverse conditions & 0.977 & 0.946 & 0.908 & 0.866 & 0.820 & 0.771 \\
\hline PSF 1 & 0.958 & 0.909 & 0.856 & 0.801 & 0.745 & 0.688 \\
\hline PSF 2 & 0.969 & 0.931 & 0.887 & 0.839 & 0.788 & 0.736 \\
\hline PSF 3 & 0.972 & 0.937 & 0.895 & 0.849 & 0.801 & 0.750 \\
\hline PSF 1 + PSF 2 + PSF 3 & 0.936 & 0.870 & 0.801 & 0.734 & 0.667 & 0.604 \\
\hline
\end{tabular}

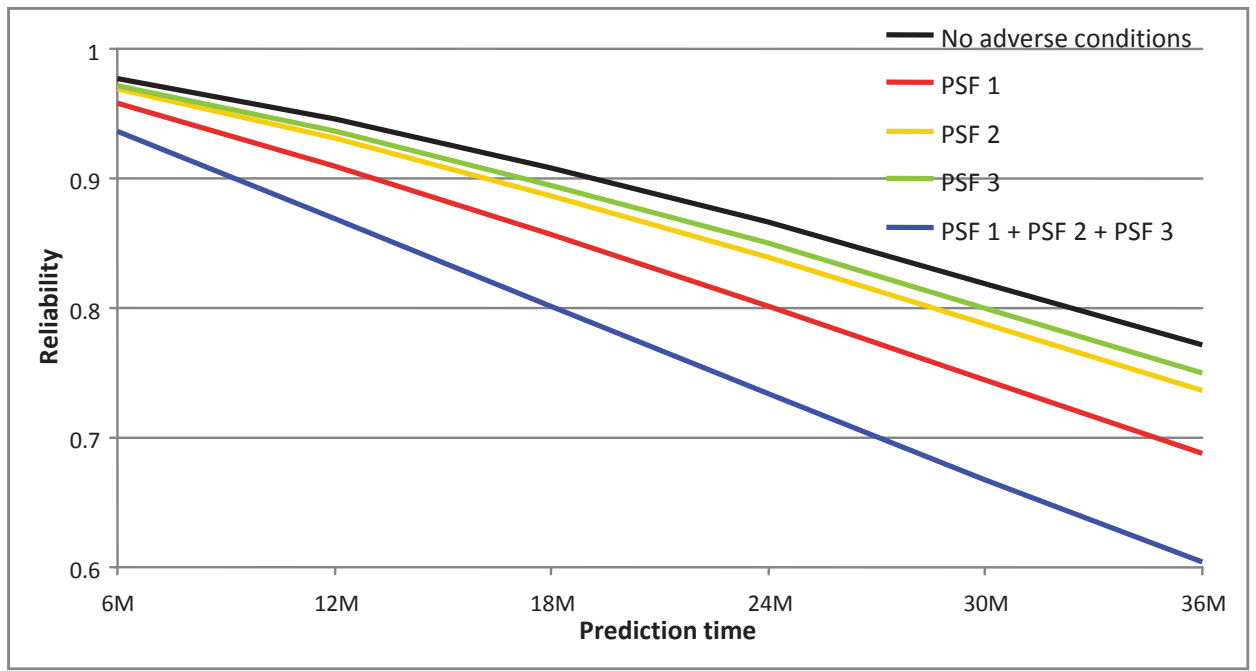

Fig. 2. Influence of environmental, ergonomic factors and properties of operator on the reliability of main engine fuel supply system

\section{Conclusions}

Marine systems in recent years have been highly automated. This decreased the negative human impact on their functioning. His duties during system operation have been reduced in order to ensure greater reliability of the system. Anyway the operator still plays an important role and has a significant impact on the reliability of the PS. Therefore, the ship propulsion systems should be treated as an antropotechnical object. In addition, results from studies show that considering operator reliability, as a value not depending on PSF may be insufficient for detailed analysis. Fig. 2 shows a clear influence of external factors and internal properties of the operator on the reliability of such systems. A combination of several PSF during performing duties by operator 
makes a significant reduction of system reliability and may adversely affect the safety of the crew, vessel and cargo located on board. Therefore, it is highly important to select a competent and skilled crew and provide them the best possible working conditions. Such actions will reduce the share of PSF in the reliability of the PS and thus will improve safety of seagoing ships and people onboard.

\section{References}

[1] Borysiewicz, M., The PSA (Probabilistic Safety Assessment) technique in defining safety regulations for nuclear power plants, Warsaw 2010.

[2] Brandowski, A., Frąckowiak, W., Mielewczyk, A., Subjective reliability estimation of the seagoing ship systems, Safety, Reliability and Risk Analysis, Proceedings of the ESREL Conference, Stavanger 2007.

[3] Brandowski, A., Frąckowiak, W., Nguyen, H., Mielewczyk, A., Propulsion risk of a seagoing ship prediction based on expert opinions, Journal of Polish CIMAC, Vol. 5, No. 2, pp. 29-40, Gdansk 2010.

[4] Brandowski, A., Frąckowiak, W., Nguyen, H., Podsiadło, A., Subjective propulsion risk of a seagoing ship estimation, Safety, Reliability and Risk Analysis, Proceedings of the ESREL Conference, Valencia 2008.

[5] Brandowski, A., Frąckowiak, W., Nguyen, H., Podsiadło, A., Risk estimation of the seagoing ship casualty as the consequences of propulsion los, Safety, Reliability and Risk Analysis, Proceedings of the ESREL Conference, Prague 2009.

[6] Gniedienko, B. W., Bielajew, J. K., Sołowiew, A. D., Mathematical methods of reliability theory, WNT, Warsaw 1968.

[7] Modarres, M., Kaminskiy, M., Krivtsov, V., Reliability Engineering and Risk Analysis, Marcel Dekker, Inc., New York 1999.

[8] Williams, J. C., Heart - A proposed method for achieving high reliability in process operation by means of human factors engineering technology in Proceedings of a Symposium on the Achievement of Reliability in Operating Plant, Safety and Reliability Society, Birmingham 1985. 